\title{
Economia criativa: novas oportunidades baseadas no capital intelectual
}

\author{
Armando Dalla Costa* \\ Elson Rodrigo de Souza-Santos**
}

\begin{abstract}
RESUMO - Nas últimas duas décadas ganhou força um novo ramo de estudo denominado "economia criativa" ou "economia cultural" que tem como foco as atividades baseadas no capital intelectual, que representa oportunidades para indivíduos, empresas, regiões e países fomentarem a geração de riquezas, impulsionar o crescimento econômico, geração de empregos e desenvolvimento. Nesse escopo podem ser colocadas atividades como design, arquitetura, turismo, produtos culturais, mídias, desenvolvimento de games, entre outros, que têm como linha mestra e principal insumo a criatividade. Estes "novos" produtos representam valores crescentes de participação na produção de riqueza e no comércio internacional. Em função de sua importância crescente, esta nova economia criativa desperta interesse de governos, através de estudos e políticas para fomentar o setor. Inicialmente esta atividade foi identificada na Austrália e GrãBretanha e depois expandiu-se para outros países, inclusive o Brasil, onde conta com apoio do SEBRAE e do BNDES. Este texto propõe-se a analisar o papel e o funcionamento desta nova parcela da economia.
\end{abstract}

Palavras-chave: Economia criativa. Criatividade. Capital intelectual.

\section{INTRODUÇÃO}

A "economia criativa" ou "economia cultural" tem como matéria-prima a criatividade, abrangendo atividades relacionadas à design, moda, arquitetura, artes, produção cultural, cinema, turismo, mídia entre outros. Em números, tomando como exemplo uma grande metrópole como Buenos Aires, a cadeia da economia criativa correspondeu a 9\% do produto gerado, 9,5\% dos empregos e à adição de US\$ 4,3 bilhões para a cidade, entre 2003-2007 (UNESCO, 2010, p. 54). No Brasil, as estimativas apontam à participação da cadeia criativa no PIB brasileiro em 2006 de cerca de 16,4\%, o equivalente a $\mathrm{R} \$ 381,3$ bilhões, impulsionados principalmente pelos segmentos de arquitetura e moda (FIRJAN, 2008).

A crescente importância da cadeia da economia criativa nas últimas décadas motivou o aumento do interesse pela área. Assim, surgiram estudos como de Scott (1997) sobre as cidades culturais, Pratt (1997), Caves (2001) e Vogel (2001), aprofundando a discussão sobre o sistema de produção das indústrias culturais e sua importância na economia, e Florida (2002),

\footnotetext{
* Doutor em História Econômica pela Universidade de Paris III. É professor do Departamento de Economia e do Programa de Pós-Graduação em Desenvolvimento Econômico da Universidade Federal do Paraná. Endereço eletrônico: ajdcosta@ufpr.br.

** Mestrando do Programa de Pós-Graduação em Desenvolvimento Econômico pela Universidade Federal do Paraná. É bolsista do CNPq. Endereço eletrônico: elson129@gmail.com.
} 
sobre a emergência de uma classe criativa. Entretanto, Howkins (2001) aparece como o autor que deu forma a economia criativa, ao vendê-la como uma maneira das pessoas transformarem ideias em dinheiro. Além desses autores, há pesquisas patrocinadas por governos e organismos multilaterais, como a da Unesco (2008), que representa um marco ao delimitar o que é e qual a importância da economia criativa nos tempos atuais.

O objetivo desse trabalho é introduzir os conceitos de economia criativa e as manifestações na vida real, encarando-as como potenciais oportunidades para crescimento de empresas e desenvolvimento econômico. Dessa forma, o trabalho está organizado em duas partes. A primeira aborda os conceitos teóricos relacionados e a delimitação do tema. A segunda ressalta as manifestações práticas com exemplos concretos em números e casos, terminando com algumas considerações finais.

\section{MARCOS CONCEITUAIS}

As expressões "indústrias criativas" e "economia criativa" são relativamente recentes, pois constituem produtos da "terceira revolução industrial" relacionados diretamente ao paradigma de produção da sociedade contemporânea baseada na era pós-industrial, pós-fordista, do conhecimento, da informação e aprendizado (MIGUEZ, 2007). Na linguagem da academia, as indústrias criativas e a economia criativa configuram um campo novo de estudo ainda em fase de solidificação, mas que despertam interesse crescente. Entretanto, Cohen et al. (2008) destacam a longa trajetória sobre duas linhas de abordagens do tema economia criativa que recentemente tendem a se fundir e complementar. Uma originada na década de 1970, focando na influência da cultura nas grandes cidades norte-americanas como Los Angeles e Nova York; e na Europa, derivada do processo de desindustrialização das grandes cidades e a busca de atividades substitutas ${ }^{1}$. A outra, dos anos 1990, quando sociólogos, geógrafos, economistas, entre outros, britânicos e norte-americanos, passam a focar a análise sobre o impacto da indústria cultural e da "classe criativa" na economia regional e nacional ${ }^{2}$.

Os primeiros registros do aprofundamento do interesse acadêmico em relação à indústria criativa são verificados na universidade australiana de Queensland University of Technology (QUT) ${ }^{3}$, que conta com duas instituições dedicadas às indústrias criativas: Creative Industries Faculty, criada em 2001 em associação com duas outras instituições australianas, e o centro de pesquisas The Institute for Creative Industries and Innovation. A despeito dos inúmeros trabalhos anteriores relacionados ao assunto, o livro de John Howkins, denominado

1 Ver Perloff (1979) e Landry (2003).

2 Ver Pratt (1997) e Vogel (2001).

3 Disponível em: <http://www.qut.edu.au/>. Acesso em: 3/6/2011. 
The creative economy: How people make money from ideas, lançado em 2001, foi capaz de lançar a ideia de que as pessoas podem transformar criatividade em dinheiro. Outros dois livros relevantes, publicados nos Estados Unidos, são os do professor de economia da Universidade de Harvard Richard Caves, intitulado Creative industries, de 2001, e de Richard Florida, denominado The rise of the creative class, de 2002.

No aspecto estatal, dois países aparecem como desbravadores ao ver a economia criativa como relevante para a economia nacional, passando a focar estudos e financiar pesquisas a respeito: Grã-Bretanha e Austrália. No primeiro, há expressivos materiais publicados, especialmente pelo Department for Culture, Media and Sport (DCMS) ${ }^{4}$, órgão do Governo Britânico responsável pelas políticas nas áreas esportiva, cultural, turística e de indústrias criativas. No segundo, são ricos os estudos, documentos, políticas e programas voltados para a economia criativa, particularmente realizados em conjunto com a Queensland University of Technology, muitos encontrados na página oficial do Department of Communications, Information Technology and the Arts (DCITA) ${ }^{5}$.

A economia criativa possui uma das classificações possíveis enunciada por Cohen et al (2008), de subdividi-la em duas dimensões: indústria cultural e ocupação cultural. A primeira é baseada nas instituições lucrativas, não lucrativas e públicas que produzem bens e serviços culturais utilizando diretamente símbolos e aspectos cultuais que incluem cinema, televisão, rádio, jornais, revistas, livros e as atividades primariamente relacionadas à educação, mas também incluso software e esportes.

A matéria-prima da economia criativa está no conceito de criatividade construído ao longo das décadas. Segundo a Unesco (2010), a criatividade fundada em várias dimensões do fenômeno e baseada na concepção individual de ideais gerados, pode ser modificada quando nasce da articulação entre as diferentes criatividades: científica, tecnológica, cultural e econômica. De acordo com John Howkins (2001), a criatividade não é monopólio dos artistas, mas está presente nos cientistas, empresários, economistas, entre outros, pois eles têm a capacidade de criar algo novo, original, pessoal, significativo e real.

$\mathrm{Na}$ extensão da criatividade, pode ser citada, como uma forma de agregar atividades relacionadas à área, a indústria criativa, termo nascido em 1994 na Austrália por meio do documento Creative Nation, mais tarde em 1997 utilizado pelo Department of Culture, Media and Sport. Segundo a UNCTAD, a definição de indústria criativa está nos círculos de criação, produção e distribuição de bens e serviços que utilizam criatividade e capital intelectual como ma-

4 Disponível em: <http://www.culture.gov.uk/>. Acesso em: 2/6/2011.

5 Disponível em: <http://www.art-search.com.au>. Acesso em: 4/6/2011. 
térias-primas, baseados em atividades de conhecimento abrangendo artes em geral, potenciais geradores de vendas do comércio e direitos de propriedade intelectual; em produtos tangíveis e intelectualmente intangíveis ou serviços artísticos com criatividade, valor econômico e objetivos de mercado constituindo uma nova dinâmica do setor. Entre as manifestações em destaque da indústria criativa (Unesco, 2008) podemos destacar:

- Patrimônio cultural: representa a identidade cultural influenciada por aspectos históricos, antropológicos e étnicos, estética e visões sociais que influenciam o patrimônio cultural, bem como os bens e serviços produzidos. Subdividido em: manifestações culturais tradicionais (festivais e celebrações) e locais culturais (bibliotecas, museus, exposições).

- Artes: inspiradas no patrimônio cultural, valores de identidade e símbolos, incluindo atividades baseadas puramente na arte e cultura. Subdividido em: artes visuais (pintura, fotografia) e artes performáticas (música ao vivo, teatro, ópera).

- Mídia: baseada na comunicação de grande audiência. Subdividido em: publicações e mídia impressa (livros e revistas) e audiovisual (filmes, televisão, rádio etc.).

Os direcionadores da demanda da indústria criativa podem ser divididos em: design (interiores, gráficas, moda); novas mídias (arquitetura, cultura e entretenimento, pesquisa e desenvolvimento); e serviços criativos e correlatos (UNESCO, 2010).

\section{MANIFESTAÇÕES E EVIDÊNCIAS}

A Unesco $(2008,2010)$ coloca a economia criativa como forma de impulsionar o crescimento econômico e representar uma alternativa para o desenvolvimento, especialmente por ter como matéria-prima base a criatividade e poder utilizar características culturais e sociais de cada país/região como vantagens no desenvolvimento e produção de bens e serviços únicos competitivos. Em termos genéricos, os benefícios da economia criativa podem ser encontrados através: i) da criação de empregos, exportação, promoção e inclusão social, diversidade cultural e desenvolvimento humano; ii) do entrelaçamento entre economia, cultura e aspectos sociais com tecnologia, propriedade intelectual e objetivos turísticos; iii) de um sistema econômico baseado no conhecimento desenvolvendo a dimensão e através da interligação entre elementos macro e micro da economia; e iv) do desenvolvimento da inovação através de políticas multi- 
disciplinares. Ao mesmo tempo, políticas de apoio por parte do governo se tornam importantes para viabilizar os negócios criativos, pois representam grande crescimento ao longo do tempo (ver Tabela 1).

TABELA 1 - CRESCIMENTO DAS EXPORTAÇÕES E IMPORTAÇÕES DA ECONOMIA CRIATIVA: $2002-2008$

\begin{tabular}{l|r|r}
\hline \multicolumn{1}{c|}{ Categoria } & Exportação (em \%) & Importação (em \%) \\
\hline Todos os serviços criativos & 17,10 & 13,00 \\
Publicidade & 18,40 & 13,90 \\
Arquitetura & 20,90 & 16,50 \\
Pesquisa e desenvolvimento de serviços & 14,80 & 13,00 \\
Cultura e serviços recreativos & 10,40 & 8,60 \\
Audiovisual e serviços relacionados & 11,00 & 8,90 \\
Outros & 7,30 & 7,90 \\
\hline
\end{tabular}

FONTE: UNESCO (2010, p. 284).

O tipo de empresa que atua no setor é prevalentemente de porte pequeno e médio, que sofre dificuldades em obter financiamento para seus projetos, pois aparentemente são mais arriscados que em outros ramos, afetando particularmente os países que possuem sistemas financeiros menos desenvolvidos. Por outro lado, as grandes empresas fazem uso das novas tecnologias de comunicação com aplicações digitais para suprir os mercados consumidores por meio de bens e serviços classificados como produtos culturais (UNESCO, 2010, p. 86). Entre as empresas criativas com uma história de sucesso, podem ser citadas a Microsoft e a Apple, que desde a década de 1980 focaram na criação de sistemas operacionais para computadores pessoais de baixo custo em que a matéria-prima para a criação dos produtos e serviços foi a criatividade.

As cidades criativas representam uma peça central no movimento do comércio em termos globais relativo a economia criativa, pois operam na dinâmica da economia, criando uma rede de cooperação e reposição de talentos em todo mundo. O surgimento e fortalecimento destas cidades criativas transforma o próprio ambiente onde se situam e promove uma dinâmica própria para este setor de atividade (LANDRY, 2003) (ver Tabela 2).

TABELA 2 - GERAÇ̃̃O DE EMPREGOS NA ÁREA DE CULTURA

\begin{tabular}{lr|r|r}
\hline \multicolumn{1}{c}{ Cidade } & Ano de referência & População (em milhões) & Empregos na área cultural (em milhares) \\
\hline Londres & 2002 & 7,4 & 525 \\
Montreal & 2003 & 2,4 & 98 \\
Nova York & 2002 & 8,1 & 309 \\
Paris & 2003 & 11,1 & 113 \\
\hline
\end{tabular}

FONTE: OCDE (2007).

Por exemplo, Mignaqui et al. (2005), ao estudarem o caso de Buenos Aires, identificam a formação de aglomerações econômicas compatíveis com a economia criativa, além dessas 
serem apoiadas pelo poder público através de instituições tais como Subsecretaría de Gestión e Industrias Culturales, Foro para la Defensa de las Industrias Culturales de Buenos Aires, Observatorio de Industrias Culturales e programas como Programa de Fomento Metropolitano de la Cultura, las Artes y las Ciencias e Programa Cultura Exporta. O objetivo é utilizar as economias criativas como forma de revitalizar regiões da cidade e reorientar as atividades econômicas.

As nações começam a ver a economia criativa como um setor relevante da economia e que possui impactos significativos. Como observa Porter (1990), a produção de bens e serviços criativos, sobre certas circunstâncias, mostra o entrosamento entre eficiência e aumento da produtividade sustentando o desenvolvimento, refletido no progresso de ambientes regionais urbanos onde a produção criativa floresce, como Londres, Nova York e Paris, e em países em desenvolvimento, como Bombaim, Hong Kong, Cidade do México e Seul.

Dada a importância da indústria criativa para o desenvolvimento e como atividade econômica, o documento da Unesco (2010, p. 262) recomenda que os governos atuem de modo a apoiar esse setor da economia. As medidas são resumidas em:

- Nível micro: analisar e mapear os impactos econômicos e sociais das indústrias criativas. Ao mesmo tempo, dar suporte às pequenas e médias empresas.

- Nível meso: comparar a análise entre as indústrias criativas e outros ramos da economia.

- Nível macro: estabelecimento de políticas sistêmicas com instrumentos institucionais para o desenvolvimento socioeconômico e fortalecimento da identidade cultural.

A meta das políticas públicas propostas pela Unesco é analisar o impacto de longo prazo das indústrias criativas nas economias nacionais.

\section{CONSIDERAÇÕES FINAIS}

A economia criativa, como verificou-se no texto, é uma área relativamente nova da economia e que ganha uma importância crescente no mundo globalizado. Merece destaque neste cenário o desenvolvimento das Novas Tecnologias da Informação e Comunicação que servem de apoio na divulgação desta nova forma de produção e de produtos inovadores.

Por outro lado, este novo rosto da economia, ao basear-se na inovação, intuição, cria- 
tividade e no lançamento de novos produtos e serviços, exige das sociedades uma atuação permanente e importante no que diz respeito à educação de sua população. Quanto mais desenvolvido for o sistema educacional e maior for o tempo de permanência na escola formal inicial, mais chances têm os países e as cidades de inovarem nos produtos e processos. Além disso, entra um elemento novo que é a formação permanente da mão de obra após a formação inicial. Trata-se dos cursos de especialização e de pós-graduação de modo geral, responsáveis pela permanente atualização desta mão de obra altamente capacitada e que precisa estar em contato com as novidades permanentes que se apresentam.

Por fim, é necessário verificar como se apresenta o Brasil diante deste novo quadro da economia. É verdade que há cidades e empresas atuando com bom nível de desempenho neste sentido, mas também há muito o que fazer, tanto por parte do poder público como dos consórcios de empresas privadas. Estes últimos aspectos serão tratados de maneira pormenorizada no próximo número da revista, com um artigo especialmente voltado para o assunto.

\section{REFERÊNCIAS}

CAVES, R. E. Creative industries: contracts between art and commerce. Cambridge: Harvard University Press, 2001.

COHEN, R.; DENATALE, D.; MARKUSEN, A.; WASSALL, G. H. Defining the creative economy: industry and occupational approaches. Forthcoming in Economic Development Quarterly, 2008.

FIRJAN. A cadeia da indústria criativa no Brasil. Estudos para o desenvolvimento do estado do Rio de Janeiro. n. 2, mai. 2008.

FLORIDA, R. The rise of the creative class. New York: Basic Books, 2002.

HOWKINS, J. The creative economy: how people make money from ideas. London: Penguin Press, 2001.

LANDRY, C. The creative city: a toolkit for urban innovators. London: Earthscan, 2003.

MIGNAQUI, I.; SZAJNBERG, D.; CICCOLELLA, P. Creative clusters in Buenos Aires city. Disponível em: <http://www.isocarp.net/Data/case_studies/686.pdf>. Acesso em: 15/5/2011.

MIGUEZ, P. Economia criativa: uma discussão preliminar. In: NUSSBAUMER, G. M. (Org.). Teorias e políticas da cultura: visões multidisciplinares. Salvador: EDUFBA. Coleção CULT, p. 96-97, 2007.

OCDE. International measurement of the economic and social importance of culture. Disponível em: < http://www.oecd.org/dataoecd/56/54/38348526.pdf>. Acesso em: 5/5/2011.

PERLOFF, H. Using the arts to improve life in the city. In: BURNS, L.; FRIEDMANN, J. (Org.). The art of planning: selected essays of Harvey S. Perloff. New York: Plenum Press, 1979

PORTER, M. E. The competitive advantage of nations. Basingstoke: Macmillan, 1990. 
PRATT, A. The cultural industries production system: a case study of employment change in Britain, 1984-91. Environmental and Planning A, v. 29, n. 11, p. 1953-1974, 1997.

SCOTT, A. J. The cultural economy of cities. International Journal of Urban and Regional Research, v. 2, p. 323-339, 1997.

UNESCO. Creative economy: report 2008. Nova York: United Nation, 2008.

UNESCO. Creative economy: report 2010. Nova York: United Nation, 2010.

VOGEL, H. Entertainment industry economics. New York: Cambridge University Press, 2001. 